\begin{tabular}{l} 
SCIENCE \& TECHNOLOGY \\
Journal homepage: http://www.pertanika.upm.edu.my/ \\
\hline PERTANIKA
\end{tabular}

\title{
Effect of Sodium Hydroxide (NaOH) Treatment on Coconut Coir Fibre and its Effectiveness on Enhancing Sound Absorption Properties
}

\author{
Ida Norfaslia Nasidi, Lokman Hakim Ismail and Emedya Murniwaty Samsudin* \\ Faculty of Civil Engineering and Built Environment, Universiti Tun Hussein Onn Malaysia, 86400 Parit Raja, \\ Batu Pahat, Johor, Malaysia
}

\begin{abstract}
Natural fibre has been conventionally and widely utilised as a sound absorber in order to replace the traditional synthetic absorber materials. In this study, coir fibre (CF) was prepared as an acoustic absorber and subjected to an additional surface treatment by using sodium hydroxide $(\mathrm{NaOH})$ at various concentrations ranging from $1 \%$ to $8 \%$. This was geared towards analysing the effect of alkalisation on the fibre morphology, diameter, and changes occurring in the $\mathrm{CF}$ functional groups, thus resulting in enhanced sound absorption properties. To this end, the fibre surface was analysed using a scanning electron microscopy (SEM) to study the surface morphology of treated and untreated CF materials, whereas the implementation of Fourier-transform infrared (FTIR) allowed an analysis of $\mathrm{CF}$ characterisation. The absorber sample was fabricated at a constant thickness of $45 \mathrm{~mm}$ and a density of $0.4 \mathrm{~g} / \mathrm{cm}^{3}$ density prior to testing for the sound absorption coefficient (SAC) by using an impedance tube. The morphology of CF revealed the treated fibres to be free of impurities including lignin and hemicellulose layer, which were removed from their surface. This finding was supported by the peak changes observed on the FTIR spectra. Furthermore, the fibre diameter was reduced as the concentrations of $\mathrm{NaOH}$ increased. The results conclusively indicated that treated $\mathrm{CF}$ at the concentrations of $7 \%$ and $8 \%$

ARTICLE INFO

Article history:

Received: 23 July 2020

Accepted: 12 October 2020

Published: 22 January 2021

DOI: https://doi.org/10.47836/pjst.29.1.37

E-mail addresses:

idalia_nasidi@yahoo.com.my (Ida Norfaslia Nasidi)

lokman@uthm.edu.my (Lokman Hakim Ismail)

$\mathrm{NaOH}$ gained the highest $\mathrm{SAC}$ values across the low and high-frequency ranges, yielding an $\alpha$ coefficient average of 0.9 and above.

Keywords: Coir, fiber diameter, fourier transform infrared (FTIR), sodium hydroxide, sound absorption coefficient, surface morphology
\end{abstract}

emedya@uthm.edu.my (Emedya Murniwaty Samsudin)

* Corresponding author 


\section{INTRODUCTION}

Today's modern era has resulted in the development of noise from the environment and transportation alike to become a source of pollution for mankind. As noise is inherently present in the physical surrounding, one cannot escape from this element; however, it should be noted that different people are not equally affected by the same noise. Regardless, excessive noise may affect human health and yield different psychological effects, which include insomnia, heart attack, and hypertension (Memon et al., 2015; Shiney \& Premlet, 2014). Collectively, these problems lead to public awareness and concerns regarding noise pollution. Following this, demands for a solution in order to counter-act against such issue has been raised, underlining the need for proper noise control to ensure human comfort, especially in a building compartment. To this end, improving the human quality of life and growing general awareness towards the environment have spurred much interest in sustainable materials such as natural fibre by previous researchers as the sound-absorbing materials as opposed to traditional synthetic materials, such as glass wool, minerals fibres, and fibreglass. In fact, the recent decades have been associated with natural fibre and its popularity over synthetic fibre due to its low cost, lightweight attribute, ample supply as a natural and renewable resource, and good mechanical properties (Berardi \& Iannace, 2015). This allowing the increasing development of more sustainable materials and support sustainability initiative. Additionally, natural fibre is a fibrous material, which can result in porous sound-absorbing materials offering excellent acoustic absorption attribute at a high-frequency range (Tang \& Yan, 2017).

According to Abdullah et al. (2015) higher fibre volume yields better absorptive properties compared to a lesser fibre volume of banana fibre and sugarcane bagasse fibre. Moreover, the combination for both types of fibre show a beneficial outcome in sound absorption improvement compared to a single fibre usage. Meanwhile, Santoni et al. (2019) had assessed the effect of treatment on the physical characteristics of a material and the effect of sound absorption performance when utilising hemp fibre. They found, finer fibre diameter due to the treatment increased the sound absorption coefficient compared to thicker fibre diameter. In another study, Taban et al. (2019) found that coir fibre with thickness $45 \mathrm{~mm}$ produced higher sound absorption than thinner sample of $25 \mathrm{~mm}$ and $35 \mathrm{~mm}$ with $\mathrm{SAC}$ value of 0.97 at $1000 \mathrm{~Hz}$. Next, the introduction of air gap during the experimental analysis at 10,20, and $30 \mathrm{~mm}$ resulted in a significantly increased SAC at a low-frequency range. Same observations made by Ying et al. (2016), where the thicker samples and the introduction of air gap exhibited higher sound absorption of coir fibre.

Theoretically, natural fibres are commonly known as a lignocellulosic material predominantly made up of cellulose, which is the most abundant biopolymer component present on earth (Kabir et al., 2012; Naidu et al., 2017). It can also be defined as a fibrous material due to its complex internal structure, thereby forming the cell wall of a plant 
(Hassan \& Badri, 2014). Despite natural fibre being acknowledged with properties such as good mechanical attributes, easy processing, occupational health benefits, and reduced environmental effect (Chandramohan \& Marimuthu, 2011), it is also associated with various well-documented drawbacks. Such disadvantages include moisture absorption, low thermal stability, and poor compatibility with a hydrophobic polymer matrix (Akhtar et al., 2016). To counter-act the aforementioned weaknesses, several studies have opted to investigate the properties of natural fibre for its improvement, namely via natural fibre surface modification by using either physical, chemical, or biological treatment.

Nevertheless, alkali treatment by using sodium hydroxide $(\mathrm{NaOH})$ is well-known as a commonly employed chemical treatment for natural fibre and typically yields good fibrematrix adhesion and improves the thermal and mechanical properties of composite (Jayabal et al., 2012). The reaction between $\mathrm{NaOH}$ and natural fibre is as shown in Equation 1.

$$
\text { Cell }-\mathrm{OH}+\mathrm{NaOH} \quad \text { Cell }-\mathrm{O}-\mathrm{Na}+\mathrm{H} 2 \mathrm{O}+\text { surface impurities }
$$

Alkali treatment of $\mathrm{NaOH}$ eliminate impurities and reduces diameter of fiber by removal the lignin ad hemicellulose layer on fiber surface (Senthamaraikannan \& Kathiresan, 2018). Despite, $\mathrm{NaOH}$ treatment would also maximize the mechanical strength of kenaf fibre and PALF reinforced composites (Feng et al., 2020). Using 5\% of $\mathrm{NaOH}$ solution, alkali-treated Ziziphus Mauritiana fibers improved on the surface roughness and influenced the bonding behavior due to the reduction of amorphous constituents (Vinod et al., 2020).

Therefore, this current work focus to find an alternatate materials which was sustainable to replace synthetic sound absorber. Although a number of studies has been devoted towards exploring the usage of natural fibre as a sound absorber, the effect of its surface treatment via $\mathrm{NaOH}$ across different concentrations is seldom reported, especially in the context of Malaysian natural fibre and natural fibre waste. Hence, this paper attempts to observe the morphological changes of coir fibre structure and its fibre diameter changes after being subjected to $\mathrm{NaOH}$ treatment in order to enhance the sound absorption properties of coconut coir fibre $(\mathrm{CF})$.

\section{MATERIALS AND METHODS}

\section{Material Preparations}

Raw CF was supplied by a local agricultural waste supplier, namely Sarjani Agro Shop Sdn. Bhd. located in Sri Medan, Batu Pahat. The CF sample was then cut to a shorter length of $\pm 2 \mathrm{~cm}$ to $5 \mathrm{~cm}$ for easy processing during the fabrication stage. To analyse the morphological and chemical changes occurring in the fibre structure and their effects towards sound absorption performance, the $\mathrm{CF}$ sample was treated using $\mathrm{NaOH}$ of different concentrations. Therefore, the control sample consisted of untreated coir fibre, while eight 
different concentrations of $\mathrm{NaOH}$ were utilised, namely $1 \%, 2 \%, 3 \%, 4 \%, 5 \%, 6 \%, 7 \%$, and $8 \%$, respectively. Next, the fibre-to-solution ratio was set to 1:20 so as to ensure the fibres were fully submerged in the $\mathrm{NaOH}$ solution and soaked for two hours. Following this, they were washed under running water for several times to eliminate any $\mathrm{NaOH}$ residue on the fibre strands, until no change in colour was observed in the drained water. Subsequently, the process of drying the fibres commenced, which was done under the sun for 2 to 3 days depending on the weather condition, before they were oven-dried for 30 minutes at the heating temperature of $110^{\circ} \mathrm{C} \pm 5^{\circ} \mathrm{C}$.

\section{Sample Preparation}

In this study, $15 \%$ of urea formaldehyde (UF) was utilised as the main adhesive material for the formation of the acoustic samples (Nasidi et al., 2018). It was provided by Evergreen Adhesive \& Chemical Sdn. Bhd., which is a prominent company specialising in woodworking adhesives and located at Parit Raja, Batu Pahat, Johor. Then, the CF sample was fabricated at a constant density of $0.4 \mathrm{~g} / \mathrm{cm}^{3}$ and $45 \mathrm{~mm}$ thickness (Samsudin et al., 2017). In particular, two sample diameters were fabricated, specifically $28 \mathrm{~mm}$ and 100 $\mathrm{mm}$, which were then fit into the prepared mould and compressed by using a hot compression machine for $15 \mathrm{~min}$ at $180^{\circ} \mathrm{C}$ using 1000 psi. Following this, the samples were removed from the machine and left at room temperature for cooling down (Figure 1), it should be noted that this was done before they were taken out from the mould to prevent any damage. In total, six samples (three samples for the $29 \mathrm{~mm}$ diameter and theree samples for $100 \mathrm{~mm}$ diameters) for each concentration were subjected to testing in the impedance tube to determine their respective acoustic absorption coefficient.

\section{Fibre Diameter}

The diameter measurement of CF samples was carried out by using a Digital Microscope Image Analyser, whereby 100 single-fibre strands were randomly selected for each concentration of treatment. Due to their irregular shapes, measurement of a single fibre was carried out in three positions, namely at the top, middle, and bottom of the fibre (Sanjay et al., 2019). Every fibre measured was cut according

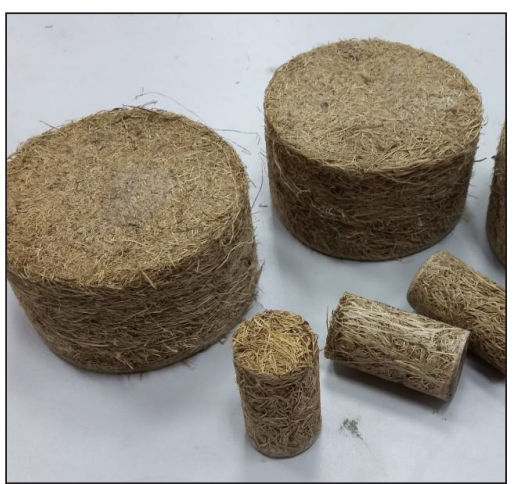

Figure 1. CF sample

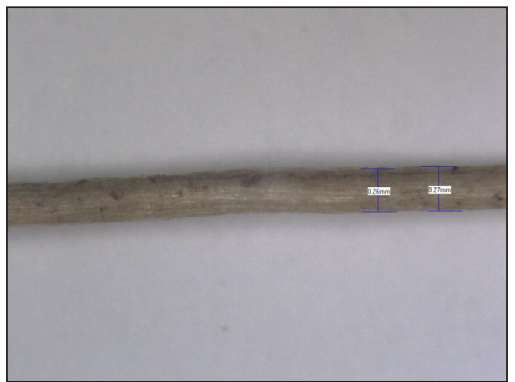

Figure 2. CF under Digital Microscope Image Analyser 
to the average length of each fibre type in order to calculate its average diameter at the three aforementioned positions to yield the actual fibre diameter. Figure 2 shows the CF diameter measurement conducted using the Digital Microscope Image Analyser.

\section{Surface Morphology Analysis}

The element of CF surface morphology was examined in this study by employing a scanning electron microscopy (SEM) using HITACHI SUI510 model. Prior to observation, the samples were coated with gold three times for $90 \mathrm{~s}$. Following this, the surface morphology analysis was carried out with an accelerating voltage of $15 \mathrm{kV}$ and $63.0 \mathrm{uA}$ emission, whereas the observation was undertaken at $500 \times$ magnification focused on the fibre structure and silica bodies present on its surface.

\section{FTIR Analysis}

Fourier-transform infrared (FTIR) is a cost-effective, rapid, non-destructive, simple, and appropriate tool for analysing the changes in fibre functional groups, whether in untreated or treated fibres alike. To this end, untreated and treated CF spectra were determined accordingly using Perkin Elmer FTIR Spectrometer LR 64912C, N3896, FTIR software V1.3.2 Perkin Elmer LX100877-1 made in the U.S.A., which was equipped with an ATR sample holder. To achieve this, the CF samples were ground into powder form less than 100 microns, which was next inserted into the powder plate until it covered the crystal glass and was slowly compacted. The process was carried out at a wavenumber ranging between $4000 \mathrm{~cm}^{-1}$ to $600 \mathrm{~cm}^{-1}$ and operated at a resolution of $4 \mathrm{~cm}^{-1}$, whereby 32 scans were collected for each sample.

\section{Sound Absorption Test}

The next phase consisted of CF sample measurement by using an impedance tube in accordance to BS ISO 10534-2 in order to measure the sound absorption coefficient (SAC). This equipment and its method of measurement are well-known as a simple approach, which is easily conducted and convenient in determining the $\alpha$ value. Measurement equipped with tubes (SCS9020B/TL), two-unit microphones, one speaker and one computer to analyse the data. The process was carried out within the range of frequency from $100 \mathrm{~Hz}$ to 5000 $\mathrm{Hz}$ in $1 / 3$ octave band. In particular, the low-frequency range testing employed a large tube with a $100 \mathrm{~mm}$ tube diameter at the frequencies spanning from $100 \mathrm{~Hz}$ to $1600 \mathrm{~Hz}$, whereas high-frequency range testing spanned from $1500 \mathrm{~Hz}$ to $5000 \mathrm{~Hz}$ by using a small tube with a $29 \mathrm{~mm}$ diameter tube size. Then, measuring the absorption coefficient in order to assess the sound absorption performance was done by placing a loudspeaker at one end of the impedance tube and a sample at its other end. During the testing, the sound waves were propagated within the tube to strike between the sample and sound source, which then reflected as a standing wave. 


\section{RESULT AND DISCUSSION}

\section{Coir Fibre Diameter}

Table 1 details a summary of the results obtained from laboratory measurements of the CF diameter. Physically, CF revealed an almost regular diameter along the entirety of the fibre strands. However, the measurement was also taken at three different locations of the strand, allowing the calculation of a mean value. The values in Table 1 reveal a larger fibre diameter for the untreated CF sample compared to the treated fibre. In particular, untreated CF yielded an average diameter ranging between $46.7 \mu \mathrm{m}$ and $260.0 \mu \mathrm{m}$, whereas its average diameter value was $124.27 \mu \mathrm{m}$. A similar result had been reported by Chen et al. (2016) when bamboo fibres were subjected to varying concentrations of $\mathrm{NaOH}$, while studies by Dittenber and Gangaroa (2012) and Geethamma et al. (1998) had observed their raw CCF diameter that ranged from $100 \mu \mathrm{m}$ to $460 \mu \mathrm{m}$. Next, the mean CF diameter was reduced after the samples were treated with different concentrations of $\mathrm{NaOH}$, which spanned from low to high concentrations. In particular, the diameter value was reduced by approximately $22.9 \%$ when its values were juxtaposed across untreated fibre to those subjected to $8 \% \mathrm{NaOH}$ concentration. Such decrement in fibre diameter is typically caused by the removal of lignin, which is generally found on the fibre surface (Hashim et al., 2017). This is supported by Pouriman et al. (2017), whereby the average diameter of a single salogo fibre was reduced from $6.23 \mu \mathrm{m}$ to $4.23 \mu \mathrm{m}$. Similarly, the alkali treatment subjected to the sample had removed some of the cellulose and lignin contents on the fibre structure, thereby causing the fibre diameter reduction.

Figure 3 depicts the cumulative distribution of 100 fibre strands of CF. The findings clearly showed a decreased fibre diameter when the alkali concentrations were increased. Furthermore, untreated fibre and those subjected to $1 \% \mathrm{NaOH}$ resulted in a larger fibre diameter, whereby the line in Figure 4 is located slightly to the right side. Meanwhile, fibres treated with $2 \%$ and $3 \% \mathrm{NaOH}$ straddled the middle range between the thicker and thinner fibre diameters, whereas $\mathrm{NaOH}$ concentration increments from $4 \%$ to $8 \%$ yielded barely-seen changes in the fibre diameter. However, it should be noted that the $7 \%$ and $8 \% \mathrm{NaOH}$ concentrations were characterised with graph lines located at the outer part of the group on the left side.

Table 1

Range of diameter and average diameter of untreated and treated CCF samples

\begin{tabular}{lccccccccc}
\hline Fiber & CF 0\% & CF 1\% & CF 2\% & CF 3\% & CF 4\% & CF 5\% & CF 6\% & CF 7\% & CF 8\% \\
\hline $\begin{array}{l}\text { Range of } \\
\text { diameter }(\mu \mathrm{m})\end{array}$ & $46.7-$ & $36.7-$ & $40.0-$ & $30.0-$ & $30.0-$ & $36.9-$ & $36.2-$ & $20.0-$ & $26.7-$ \\
\hline $\begin{array}{l}\text { Average } \\
\text { Diameter }(\mu \mathrm{m})\end{array}$ & 124.3 & 123.9 & 112.9 & 105.9 & 104.8 & 103.4 & 101.1 & 98.8 & 95.8 \\
\hline
\end{tabular}




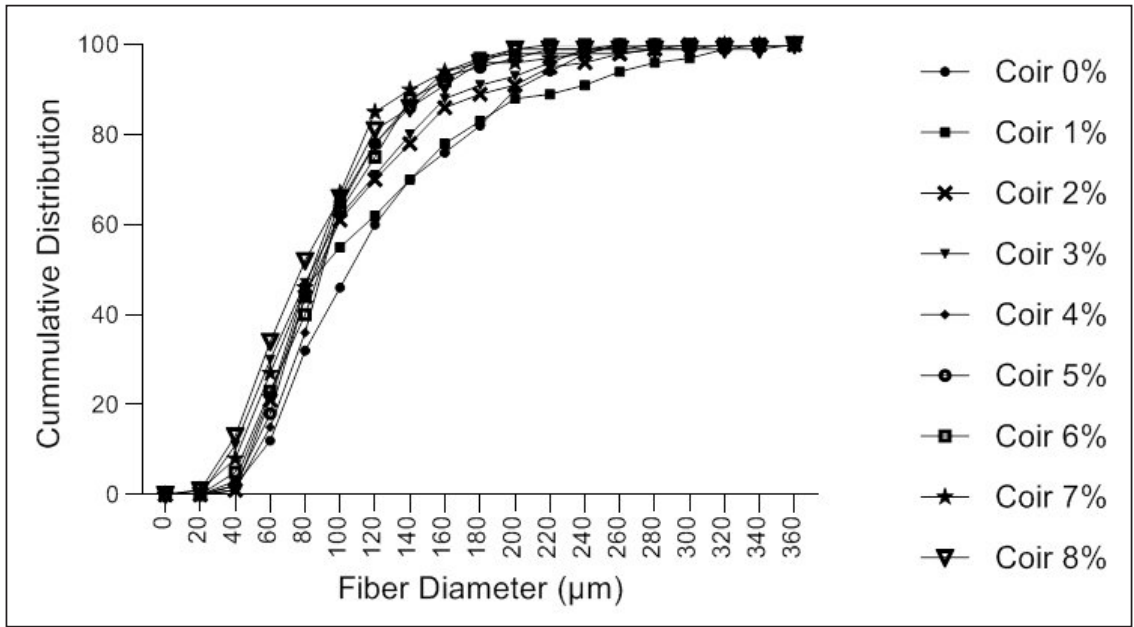

Figure 3. Cumulative distribution of $\mathrm{CF}$

\section{Surface Morphology of CCF}

Figures 4 (a) - (i) reveal the surface morphologies of untreated and treated CF samples ranging from $1 \%$ to $8 \% \mathrm{NaOH}$ concentrations, which were analysed using SEM. For example, the untreated CF fibre strand is shown in Figure 4(a) in which it is fully covered by impurities and has uneven surfaces. Besides, its components included pectin, wax, lignin, and silica bodies, which paralleled the observations of $\mathrm{Ng}$ et al. (2018). Removal of impurities could be seen as compared to the untreated fibers. It shows gradual changes in the effect of $\mathrm{NaOH}$ treatment on the coir fiber surface. Meanwhile, treated CCF samples subjected to $\mathrm{NaOH}$ concentrations ranging from $1 \%$ to $3 \%$ (Figure 4 (b)-(d)) showed a partial removal of the impurities, including silica bodies, which left tiny holes on the sample surfaces. These tiny holes are associated with the creation of microcompartments, which are good for sound dissipation purposes (Mercado et al., 2018). Therefore, this shows that a low concentration of $\mathrm{NaOH}$ does not significantly affect the removal of impurities present on the fibre (Hashim et al., 2017). Subsequently, an increased concentration of $\mathrm{NaOH}$ treatments subjected to higher concentrations from $4 \%$ (Figure $4(\mathrm{e})$ ) to $6 \%$ (Figure $4(\mathrm{~g})$ ) allowed the remaining silica bodies to be completely removed. As a result, it created pores that appeared due to the removal of the silica bodies, which looked larger with an uneven depth. Similar findings had also been discovered by $\mathrm{Ng}$ et al. (2018), which further increased the mechanical bonding between the coir fibre and matrix during the fabrication proces (Karthikeyan et al., 2014). Additionally, some longitudinal pits were observed along the fibre strands assessed in this study, thereby paralleling the same phenomenon described by (Manjula et al., 2017). However, as the $\mathrm{NaOH}$ concentrations increased to 7\% and $8 \%$ (Figure 4 (h)-(i)), these previously created pores disappeared almost completely. This may be attributable to the surface layer CF removal (Leão et al., 2015) Besides, the 
morphological results indicated the CF fibres had rough surfaces and were clean from any impurities as the $\mathrm{NaOH}$ concentration was increased. To support the argument regarding alkali treatment effectiveness, FTIR spectroscopy was employed to investigate the structural changes observed on the CF sample surface before and after treatment.

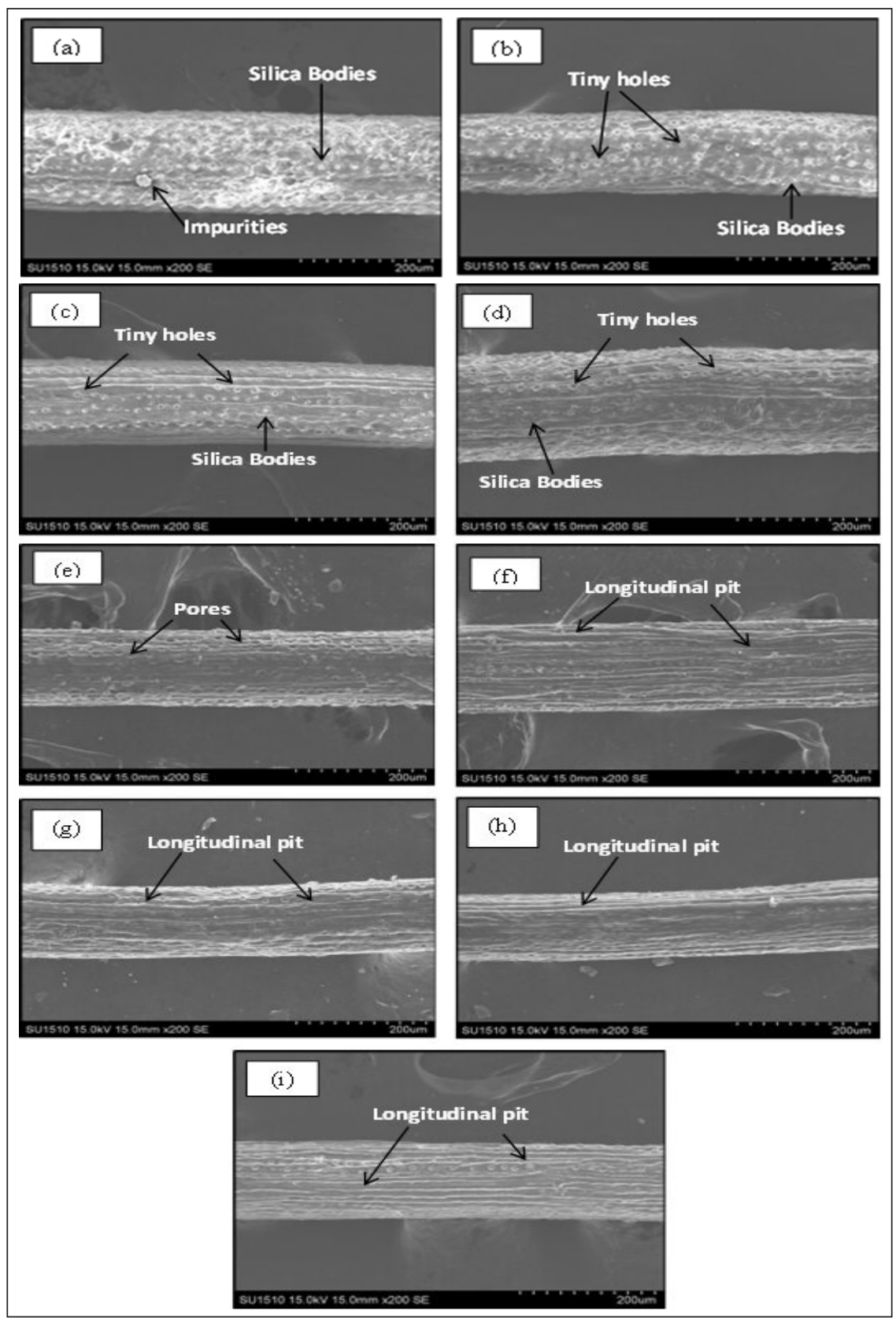

Figure 4. SEM images on surface of CF : (a) $\mathrm{CF} 0 \%$, (b) $\mathrm{CF} 1 \%$ (c) $\mathrm{CF} 2 \%$, (d) $\mathrm{CF} 3 \%$, (e) $\mathrm{CF} 4 \%$, (f) $\mathrm{CF} 5 \%$, (g) $\mathrm{CF} 6 \%$, (h) $\mathrm{CF} 7 \%$, and (i) $\mathrm{CF} 8 \%$ 


\section{FTIR Analysis}

Figure 5 represents the FTIR spectra observed for the untreated and treated CF samples, ranging from $1 \%$ to $8 \%$ concentrations. First, the peak ranging from $3000 \mathrm{~cm}^{-1}$ to 3700 $\mathrm{cm}^{-1}$ corresponded to the $\mathrm{O}-\mathrm{H}$ stretching of hydroxyl groups (Krishnan \& Ramesh, 2013; Siakeng et al., 2018). In this study, the untreated CF gained its $\mathrm{O}-\mathrm{H}$ peak at band $3345 \mathrm{~cm}^{-1}$ in which the observations clearly and contrastingly depicted a significantly reduced intensity for alkali-treated sample. The diminished intensity may be attributed to the breaks of hydrogen bonding present in $\mathrm{OH}$ groups during the $\mathrm{NaOH}$ treatments (Yew et al., 2019). Meanwhile, the absorption band corresponding to the $\mathrm{C}=\mathrm{O}$ stretching of carboxyl and acetyl groups in the hemicellulose yielded the raw CF peak band at 1735 $\mathrm{cm}^{-1}$. However, it disappeared when the fibres were treated with $\mathrm{NaOH}$, which could be linked to hemicellulose solubility property in an alkaline solution and thus caused its disappearance (Yew et al., 2019). The same observations had also been made by Abraham et al. (2013), wherein a peak was present at band $1249 \mathrm{~cm}^{-1}$ for the untreated CF sample and attributable to the aromatic ring skeletal vibration and $\mathrm{C}=\mathrm{O}$ stretching of lignin. However, the peak for treated fibre samples was not completely removed; its intensity was merely decreased. Therefore, this is indicative of some lignin and hemicellulose content removed via the $\mathrm{NaOH}$ treatment from the fibre surfaces and supports the fibre diameter decrements outcomes observed after subjected to the treatment.

\section{Sound Absorption Coefficient (SAC)}

Figure 6 illustrates the sound absorption performance generated by untreated and $\mathrm{NaOH}-$ treated CF samples, which range from $1 \%$ to $8 \%$. The findings revealed that as the frequency increased, the SAC values were also amplified in line with the outcomes from (Taban et

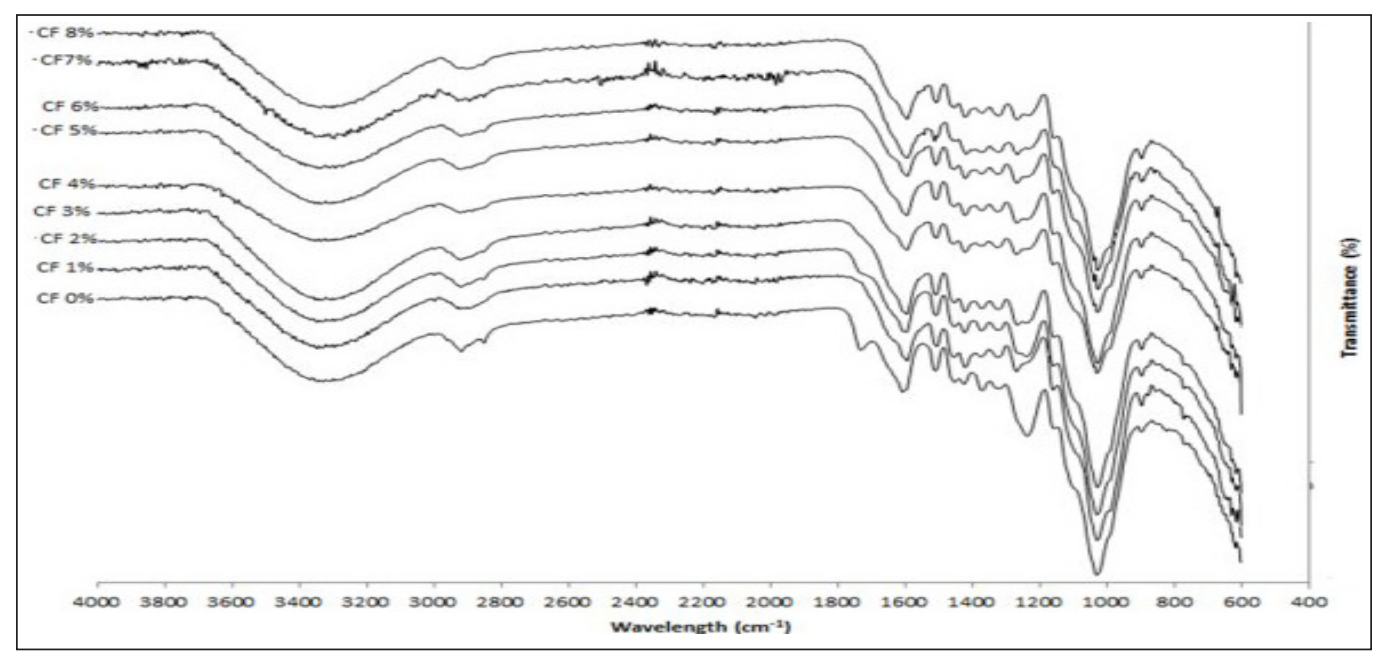

Figure 5. FTIR spectrum of raw and alkali treated CF 
al., 2019). Furthermore, the result shows that from, untreated and treated CF samples alike yielded superior acoustic absorption ability at the frequency ranging from $500 \mathrm{~Hz}$ to $5000 \mathrm{~Hz}$. Besides, the SAC values obtained for all samples were higher than 0.5 , thereby indicating that over $50 \%$ of the incident sound was absorbed. The figure further shows that the peak absorption at a lower frequency region is gained by $\mathrm{CF}$ samples treated with high $\mathrm{NaOH}$ concentrations. In particular, samples subjected to $7 \%$ and $8 \% \mathrm{NaOH}$ yielded $\alpha=$ 0.98 at the frequency of $1250 \mathrm{~Hz}$. Upon entering the middle frequency region, the SAC value for all CF samples was decreased, revealing the least absorptive value as low as 0.72. In contrast, the highest sound absorption performance was obtained by an untreated $\mathrm{CF}$ sample in the middle frequency range, indicating its status as a good absorber from the middle to the beginning of the high-frequency range in comparison with treated fibres. Here, the SAC values recorded ranged from 0.83 to 0.96 at frequencies between $2000 \mathrm{~Hz}$ to $4000 \mathrm{~Hz}$. Lastly, the high-frequency sector revealed the highest SAC values obtained at the higher $\mathrm{NaOH}$ concentrations (i.e. $7 \%$ and $8 \%$ ), while other samples also observed an increased sound absorption performance. This outcome is significantly attributable to the finest diameter of fibre treated with the highest $\mathrm{NaOH}$ concentrations through the removal of impurities, lignin and hemicellulose layer on fiber surfaces, thus enhancing the SAC outcomes at the low and high-frequency ranges (Wang et al., 2015). Similar outcome was discovered by Samaei et al. (2020), where the decrement on fiber diameter due to $\mathrm{NaOH}$ treatment increased the sound absorption performances of kenaf fiber at constant thickness and density. Theoretically, fiber diameter was the one factor that influencing the sound absorption of fibrous materials. This was due to the more tortuous path and higher airflow

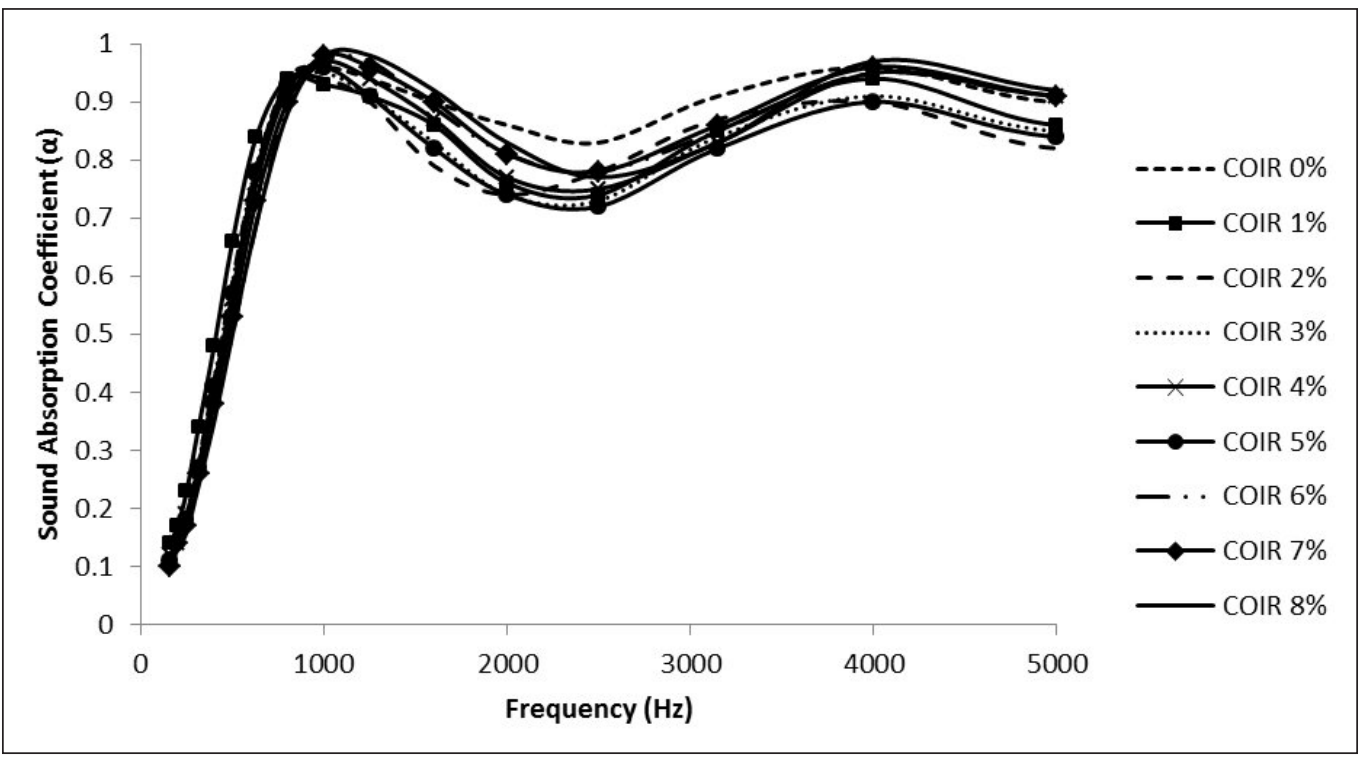

Figure 6. Sound absorption performance of $\mathrm{CF}$ at different concentrations of $\mathrm{NaOH}$ treatment 
resistance caused by higher fibre volume needed to reach equal volume of fibre with same thickness and density (Seddeq, 2009). Further analysis was made to see the correlation between acoustical performances and fibre diameter of coir fibre. It was observed that there was a positive correlation between the two variables where $r=0.754$. Overall, $C F$ implementation led to good absorption performance and the material was thus considered a good absorber.

\section{CONCLUSION}

In this work, $\mathrm{CF}$ was utilised as a sound absorber material, whereby its surface fibre was subjected to treatment using $1 \%$ to $8 \% \mathrm{NaOH}$ concentrations. Accordingly, the morphological changes, fibre diameter, and fibre composition were observed and analysed in evaluating its characteristics and sound absorption performance. In brief, $\mathrm{NaOH}$-treated CF samples yielded enhanced sound absorption performances in comparison with the untreated sample, whereby a higher $\mathrm{NaOH}$ concentration led to better performance. This is caused by its finer fibre diameter in which an absorber sample requires a higher amount of fibre to have the same weight as a thicker fibre sample, thus allowing more sound energy to be dissipated. Furthermore, the average fibre size decreased when the alkali concentrations were increased, whereas the surface morphology analysis revealed the partial removal of certain impurities at a certain amount from the fibre surface, which included lignin and hemicellulose. Up until 8\% $\mathrm{NaOH}$ concentration, clear fibre was observed and supported further by the accompanying FTIR peak spectra results. Hence, the results obtained in this study suggested for the use of $7 \%$ and $8 \% \mathrm{NaOH}$ concentrations in order to optimally implement a coconut fibre treatment approach geared for maximum sound absorption performance.

\section{ACKNOWLEDGMENTS}

Special thanks to Research Management Centre (RMC) Universiti Tun Hussein Onn Malaysia, for the funding of this research under vote E15501 and vote U791.

\section{REFERENCES}

Abdullah, A. H., Azharia, A., \& Salleh, F. M. (2015). Sound absorption coefficient of natural fibres hybrid reinforced polyester composites. Jurnal Teknologi, 76(9), 31-36. doi: 10.11113/jt.v76.5643

Abraham, E., Deepa, B., Pothen, L. A., Cintil, J., Thomas, S., John, M. J., .. \& Narine, S. S. (2013). Environmental friendly method for the extraction of coir fibre and isolation of nanofibre. Carbohydrate Polymers, 92, 1477-1483. doi: https://doi.org/10.1016/j.carbpol.2012.10.056

Akhtar, M. N., Sulong, A. B., Radzi, M. K. F., Ismail, N. F., Raza, M. R., Muhamad, N., \& Khan, M. A. (2016). Influence of alkaline treatment and fiber loading on the physical and mechanical properties of kenaf/ 
polypropylene composites for variety of applications. Progress in Natural Science: Materials International, 26(6), 657-664. doi: https://doi.org/10.1016/j.pnsc.2016.12.004

Berardi, U., \& Iannace, G. (2015). Acoustic characterization of natural fibers for sound absorption applications. Building and Environment, 94, 840-852. doi: https://doi.org/10.1016/j.buildenv.2015.05.029

Chandramohan, D., \& Marimuthu, K. (2011). A review on natural fibers. International Journal of Research and Reviews in Applied Sciences, 8(2), 194-206.

Chen, H., Yu, Y., Zhong, T., Wu, Y., Li, Y., Wu, Z., \& Fei, B. (2016). Effect of alkali treatment on microstructure and mechanical properties of individual bamboo fibers. Cellulose, 24(1), 333-347. doi: https://doi. org/10.1007/s10570-016-1116-6

Dittenber, D. B., \& Gangarao, H. V. S. (2012). Critical review of recent publications on use of natural composites in infrastructure. Composites: Part A, 43(8), 1419-1429. doi: https://doi.org/10.1016/j. compositesa.2011.11.019

Feng, N. L., Malingam, S. D., Razali, N., \& Subramonian, S. (2020). Alkali and silane treatments towards exemplary mechanical properties of kenaf and pineapple leaf fibre-reinforced composites. Journal of Bionic Engineering, 17, 380-392. doi: https://doi.org/10.1007/s42235-020-0031-6

Geethamma, V. G., Mathew, K. T., Lakshminarayanan, R., \& Thomas, S. (1998). Composite of short coir fibres and natural rubber: effect of chemical modification, loading and orientation of fibre. Polymer, 39(6-7), 1483-1491. doi: https://doi.org/10.1016/S0032-3861(97)00422-9

Hashim, M. Y., Amin, A. M., Marwah, O. M. F., Othman, M. H., Yunus, M. R. M., \& Ng, C. H. (2017). The effect of alkali treatment under various conditions on physical properties of kenaf fiber. Journal of Physics: Conference Series, 914, 1-15. doi: https://doi.org/10.1088/1742-6596/914/1/012030

Hassan, N. S., \& Badri, K. (2014). Lignin recovery from alkaline hydrolysis and glycerolysis of oil palm fiber. AIP Conference Proceedings 1614(1), 433-438. doi: https://doi.org/10.1063/1.4895236

Jayabal, S., Sathiyamurthy, S., Loganathan, K. T., \& Kalyanasundaram, S. (2012). Effect of soaking time and concentration of $\mathrm{NaOH}$ solution on mechanical properties of coir-polyester composites. Bulletin of Materials Science, 35(4), 567-574. doi: https://doi.org/10.1007/s12034-012-0334-2

Kabir, M. M., Wang, H., Lau, K. T., \& Cardona, F. (2012). Chemical treatments on plant-based natural fibre reinforced polymer composites: An overview. Composites: Part B, 43, 2883-2892. doi: https://doi. org/10.1016/j.compositesb.2012.04.053

Karthikeyan, A., Balamurugan, K., \& Kalpana, A. (2014). The effect of SLS treatment on tensile property of coconut fiber reinforced epoxy composites. Transactions of Mechanical Engineering, 38(1), 157-166.

Krishnan, V. N., \& Ramesh, A. (2013). Synthesis and characterization of cellulose nanofibers from coconut coir fibers. IOSR Journal of Applied Chemistry (IOSR-JAC), 6(3), 18-23.

Leão, R. M., Luz, S. M., Araujo, J. A., \& Novack, K. (2015). Surface treatment of coconut fiber and its application in composite materials for reinforcement of polypropylene. Journal of Natural Fibers, 12(6), 574-586. doi: https://doi.org/10.1080/15440478.2014.984048 
Manjula, R., Raju, N., Chakradhar, R., \& Johns, J. (2017). Effect of thermal aging and chemical treatment on tensile properties of coir fiber. Journal of Natural Fibers, 15(1), 112-121. doi: https://doi.org/10.1080/ 15440478.2017 .1321513

Memon, H., Abro, Z. A., Ahmed, A., \& Khoso, N. A. (2015). Considerations while designing acoustic home textiles: A review. Journal of Textile and Apparel, Technology and Management, 9(3), 1-29.

Mercado, R. D. T., Ureta, R. M., \& Templo, R. J. D. (2018). The potential of selected agricultural wastes fibers as acoustic absorber and thermal insulator based on their surface morphology via scanning electron microscopy. World News of Natural Sciences, 20, 129-147.

Naidu, A. L., Jagadeesh, V., \& Bahubalendruni, M. V. A. R. (2017). A review on chemical and physical properties of natural fiber reinforced composites. International Journal of Advanced Research in Engineering and Technology (IJARET), 8(1), 56-68.

Nasidi, I. N., Ismail, L. H., Samsudin, E. M., Abdul Khodir, M. F., \& Kamarozaman, M. A. (2018). The Effect of Different Fibre Length and Different Urea Formaldehyde (UF) content on Sound Absorption Performance of Empty Fruit Bunch (EFB). MATEC Web of Conferences, 150, 1-5. doi: https://doi. org/10.1051/matecconf/201815003003

Ng, Y. R., Shahid, S. N. A. M., \& Nordin, N. I. A. A. (2018). The effect of alkali treatment on tensile properties of coir / polypropylene biocomposite. IOP Conference Series: Materials Science and Engineering, 368, 1-8. doi: https://doi.org/10.1088/1757-899X/368/1/012048

Pouriman, M., Caparanga, A. R., Ebrahimi, M., \& Dahresobh, A. (2017). Characterization of untreated and alkaline-treated salago fibers (Genus wikstroemia spp.). Journal of Natural Fibers, 15(2), 296-307. doi: https://doi.org/10.1080/15440478.2017.1329105

Samaei, S. E., Mahabadi, H. A., Mousavi, S. M., Khavanin, A., Faridan, M., \& Taban, E. (2020). The influence of alkaline treatment on acoustical, morphological, tensile, and thermal properties of Kenaf natural fibers. Journal of Industrial Textiles, O(0), 1-25. doi: https://doi.org/10.1177/1528083720944240

Samsudin, E. M., Ismail, L. H., Kadir, A. A., \& Nasidi, I. N. (2017, July 23-27). Thickness, density, and porosity relationship towards sound absorption performance of mixed palm oil fibers. In 24th International Congress on Sound and Vibration (pp. 1-8). London, UK.

Sanjay, M. R., Siengchin, S., Parameswaranpillai, J., Jawaid, M., Pruncu, C. I., \& Khan, A. (2019). A comprehensive review of techniques for natural fibers as reinforcement in composites: Preparation, processing and characterization. Carbohydrate Polymers, 207, 108-121. doi: https://doi.org/10.1016/j. carbpol.2018.11.083

Santoni, A., Bonfiglio, P., Fausti, P., Marescotti, C., Mazzanti, V., Mollica, F., \& Pompoli, F. (2019). Improving the sound absorption performance of sustainable thermal insulation materials: Natural hemp fibres. Applied Acoustics, 150, 279-289. doi: https://doi.org/10.1016/j.apacoust.2019.02.022

Seddeq, H. S. (2009). Factors influencing acoustic performance of sound absorptive materials. Australian Journal of Basic and Applied Sciences, 3(4), 4610-4617.

Senthamaraikannan, P., \& Kathiresan, M. (2018). Characterization of raw and alkali treated new natural cellulosic fiber from Coccinia grandis. L. Carbohydrate Polymers, 186, 332-343. doi: https://doi. org/10.1016/j.carbpol.2018.01.072 
Shiney, A., \& Premlet, B. (2014). Acoustic properties of composite coir mats. IOSR Journal of Applied Physics, $6(3), 18-23$.

Siakeng, R., Jawaid, M., Ariffin, H., \& Salit, M. S. (2018). Effects of surface treatments on tensile, thermal, and fibre-matrix bond strength of coir and pineapple leaf fibres with poly lactic acid. Journal of Bionic Engineering, 15(6), 1035-1046. doi: https://doi.org/10.1007/s42235-018-0091-z

Taban, E., Tajpoor, A., Faridan, M., Samaei, S. E., \& Beheshti, M. H. (2019). Acoustic absorption characterization and prediction of natural coir fibers. Acoustics Australia, 47(1), 67-77. doi: https://doi. org/10.1007/s40857-019-00151-8

Tang, X., \& Yan, X. (2017). Acoustic energy absorption properties of fibrous materials: A review. Composites Part A: Applied Science and Manufacturing, 101, 360-380. doi: https://doi.org/10.1016/j. compositesa.2017.07.002

Vinod, A., Vijay, R., Singaravelu, D. L., Khan, A., Sanjay, M., Siengchin, S., .. \& Asiei, A. M. (2020). Effect of alkali treatment on performance characterization of Ziziphus mauritiana fiber and its epoxy composites. Journal of Industrial Textiles, O(0), 1-3. doi: https://doi.org/10.1177/1528083720942614

Wang, X., Li, Y., Chen, T., \& Ying, Z. (2015). Research on the sound absorption characteristics of porous metal materials at high sound pressure levels. Advances in Mechanical Engineering, 7(5), 1-7. doi: https://doi. org/10.1177/1687814015575429

Yew, B. S., Muhamad, M., Mohamed, S. B., \& Wee, F. H. (2019). Effect of alkaline treatment on structural characterisation, thermal degradation, and water absorption ability of coir fibre polymer composites. Sains Malaysiana, 48(3), 653-659. doi: http://dx.doi.org/10.17576/jsm-2019-4803-19

Ying, L. Z., Putra, A., Nor, M. J. M., Muhammad, N., \& Yaakob, M. Y. (2016, July 10-14). Sound absorption of multilayer natural coir and kenaf fibers. In 23rd International Congress on Sound and Vibration (pp. 1-7). Athens, Greece. 